\section{Agência material recíproca: uma ecologia para os estudos de ciência}

\section{Reciprocal material agency: an ecology for studies of science}

\section{Carlos Alvarez Maia}

Professor, Departamento de História/ Universidade do Estado do Rio de Janeiro. Rua São Francisco Xavier, 524, $9^{\circ}$ andar 20550-900 - Rio de Janeiro - RJ - Brasil alvarez@iis.com.br

Recebido para publicação em março de 2015. Aprovado para publicação em julho de 2015.

http://dx.doi.org/10.1590/S0104-59702017000200008
MAIA, Carlos Alvarez. Agência material recíproca: uma ecologia para os estudos da ciência. História, Ciências, Saúde Manguinhos, Rio de Janeiro, v.24, n.2, abr.-jun. 2017, p.447-464.

\section{Resumo}

Há dicotomias consolidadas na historiografia das ciências que impedem um melhor desenvolvimento das pesquisas. As rupturas mental-material, sujeito-objeto e natureza-sociedade são os obstáculos. Há ainda o embaraço do conflito entre o relativismo e o realismo que acirra essas dicotomias e nelas se fundamenta. O objetivo deste artigo é enfrentar essas querelas e delas se desfazer, ultrapassando-as. A solução apresentada é a consideração do agenciamento das coisas materiais ao lado da ação dos sujeitos humanos. Um estorvo a essa proposta é a orientação de Latour que simula esse resultado por meio de uma retórica hilozoísta. Mostra-se aqui uma alternativa a Latour, desprovida de qualquer animismo, que evidencia a maneira concreta como a agência material dos objetos participa do fazer científico ao lado dos humanos.

Palavras-chave: agência material; relativismo-realismo; sociologia do conhecimento; interação sujeito-objeto; agenciamento recíproco.

\section{Abstract}

In the historiography of the sciences there are consolidated dichotomies that can hinder better research. Fissures include mental-material, subject-object and naturesociety, and the bitter conflict between relativism and realism that draws on these dichotomies and can block research. The aim of this article is to tackle these disputes, to unravel them and to move on. The proposed solution is to give consideration to the agency of material things alongside the actions of human subjects. One obstacle is presented by Latour who simulates this result by means of hylozoistic rhetoric. Here, an alternative to Latour is presented, containing no elements of animism, which gives evidence of the concrete way in which the material agency of objects participates in the doing of science, alongside humans.

Keywords: material agency; relativismrealism; sociology of knowledge; subjectobject interaction; reciprocal agency. 
$\mathrm{C}^{a}$ ada seção deste artigo é um passo da estratégia argumentativa empregada. O objetivo final é apresentar uma alternativa para historiar as ciências que supere as dicotomias natureza-sociedade e sujeito-objeto, ambas alimentadas pela disputa entre o realismo e o relativismo. Começamos com a crítica ao idealismo conduzida por uma orientação pragmática e, em seguida, convocamos os objetos a entrar em cena. A proposta é fazer uma história da ciência com sujeito e com objeto. Aqui já aparecem os problemas da solução de Latour, que persegue o mesmo objetivo deste artigo.

Na terceira seção introduz-se a "agência material", como deseja o realismo; entretanto, essa agência também é simbólica, isto é, ela "afeta" os sujeitos tornando-os ativos em suas decisões, como ocorre no relativismo. Há, assim, uma alternância entre relativismo e realismo. O próximo passo é mostrar a integração entre sujeito e objeto por meio do conceito marxista de "trabalho". Dessa forma, a oscilação entre relativismo e realismo parece buscar uma síntese heterodoxa. Vê-se que sujeito e objeto são interdependentes e, assim, sociedade e natureza se complementam.

Chegamos ao núcleo de nossa argumentação na quinta seção: com ênfase no registro simbólico, mostra-se que a prática humana se dá pela "linguagem mais que literal" em que os objetos são agentes de significação; trata-se, porém, de uma significação dada pelos sujeitos.

Na sexta seção completa-se o ciclo que integra o mundo material com o mundo simbólico pelo encontro etnográfico das coisas com as palavras e, mais uma vez, há o embate sem vencedores entre realismo e relativismo. Por fim, na última, todos os agentes, sejam pessoas, objetos ou coisas, mostram-se agentes ativos - necessários a uma história das ciências adequada aos desafios de nossa contemporaneidade.

\section{A herança idealista}

Há alguns desafios para os estudos de ciência no século XXI. Um deles é o trio de dicotomias já consolidadas na historiografia - sujeito-objeto, mental-material e sociedade-natureza - que ganham força de verdade evidente. Esse tríptico é responsável por uma grande variedade de equívocos interpretativos. Cada uma dessas dicotomias apresenta uma ruptura ficcional ao produzir entidades separadas em que, na verdade, há fusão e integração. Ora, não há mente extraída de seu corpo, nem social fora do natural e, menos ainda, sujeito isolado do objeto que o abastece e mobiliza. Essas partições são atos de violência idealista contra a descrição histórica.

Não se pode confundir o que seria uma simples estratégia de análise com uma proposição realista. O artifício de reduzir a complexidade do todo a entidades isoladas artificialmente é aceitável; entretanto, é um grave equívoco considerar esse ardil estratégico uma descrição fiel da realidade. Ao considerar independentes as partes, deixa-se de entender justamente o caráter interativo entre elas. Perde-se a ecologia da situação examinada, perde-se o aspecto relacional dessas entidades. Pensada como uma estratégia, não há simulação realista, mas, sim, uma postura pragmática plausível. Aquelas dicotomias resultam de uma vitória do idealismo que conflita com a demanda pragmática de nossos dias. Nosso olhar materialista e pragmático solicita a presença da descrição etnográfica no lugar de quaisquer artifícios idealistas. 
Outro sério problema decorreu da renovação historiográfica trazida pelo "programa forte" de David Bloor (1991), em 1976, ao propor seu princípio de simetria entre verdade e erro. Até esse momento, os estudos de ciência consideravam as verdades da ciência questões epistemológicas, e os erros é que deveriam sofrer uma análise sociológica. Essa foi a era da "sociologia do erro", 1 quando se pensava que a intervenção da sociedade macularia a objetividade do método científico, que, por si, seria o garante da verdade do saber sobre a natureza. Um grande mérito do "programa forte" foi a demonstração de que não só os erros, mas também as verdades científicas, eram alcançados por meio das relações sociais. Pairava, entretanto, uma ameaça: a produção do conhecimento científico passou a ser entendida preferencialmente como uma construção social, o que criava uma ambiguidade na qual os agentes humanos poderiam ser considerados os únicos atores. E deu-se então um grave problema. Os críticos de Bloor diziam que o conhecimento sobre a natureza seria decorrente, nesse construtivismo, de uma decisão tomada tão somente na esfera da sociedade, com base no acordo e na negociação dos humanos entre si. Dessa forma, a natureza desaparecia do cenário das interrogações científicas, que se restringiam ao acordo intersubjetivo forjado pelos atores sociais. O objeto natural perdia seu estatuto de fonte das afirmações e validações científicas. A sociedade "decidia" como o mundo devia ser. Bloor, evidentemente, discordava dessas simplificações, mas seu trabalho terminou por alicerçar uma nova tendência na historiografia que foi caracterizada pelos seus críticos como um reducionismo sociológico. ${ }^{2}$

Não tardou para esse evento produzir graves turbulências na historiografia. Perguntava-se "e a natureza não participa?" (Kuhn, 2006, p.133 e seg.), "somente há humanos, e os não humanos?" (Callon, 1986; Latour, 1994, 2001). Antes de Bloor fora razoável compreender a prática científica como se fosse uma "ciência sem sujeito", uma ciência objetiva, como solicitava o realismo científico. Nesse idealismo, o sujeito-autor era oculto, na tentativa ingênua de escapar das relações etimológicas nefastas que articulam os termos "subjetivo" e "subjetividade" com o termo "sujeito". Pensava-se evitar o subjetivismo por meio da relação, ainda etimológica, do objeto com a objetividade. A ênfase dada ao objeto transformava o sujeito em um mero leitor passivo do "livro da natureza". Com Bloor, entretanto, alcançavase o entendimento de uma "ciência com sujeito", porém seus críticos diziam que se tratava de uma "ciência sem objeto". "A própria natureza, seja lá o que for isso, parece não ter papel algum no desenvolvimento das crenças a seu respeito" (Kuhn, 2006, p.139). Perdia-se a âncora objetivista que fixava a verdade científica no objeto natural.

Se o início do século XX foi caracterizado pelo realismo de uma ciência com objeto e sem sujeito, o fim do século o foi pelo relativismo da ciência dominada pelo sujeito, porém sem objeto. O desafio que se coloca, hoje, é ir além, avançar por novas trilhas, sem cair no idealismo realista nem no relativismo sociológico.

Como fazer uma história da ciência com sujeito e com objeto?

\section{Os objetos entram em cena}

Um obstáculo a ser vencido pelo resgate do objeto para o cenário de uma ciência com sujeito é ultrapassar alguns entendimentos já sedimentados nas ciências sociais. Desde Dilthey, influenciado pela ruptura natureza-sociedade, firmou-se a oposição entre as ciências 
da natureza, Naturwissenschaften, e as ciências do espírito ou ciências históricas do homem, Geisteswissenschaften. Essa divisão implicava procedimentos distintos para cada área do saber. Considera-se a sociedade permeada por relações intencionais entre indivíduos, o que solicita a compreensão empática como modelo de entendimento para as ciências históricas. Já na natureza, os seus objetos estão articulados por relações de causalidade; um evento é causa de outro, o seu efeito, o que nos traz como modelo de entendimento a explicação causal. Não há como conciliar os dois procedimentos, a intencionalidade humana e a causalidade natural. Necessitamos de uma teoria da ação que atenda ambos os casos, de preferência uma "teoria" embasada etnograficamente, como nosso olhar pragmático solicita. Há que considerar tanto o sujeito intencional quanto o objeto em suas relações causais como agentes.

Para as ciências sociais, que já utiliza o conceito de "agência", o obstáculo é compreender o que seria uma agência para as coisas materiais - tal conceito encontra-se restrito às ações humanas por meio da intencionalidade. $\mathrm{O}$ agente seria aquele que realiza o movimento com a intenção de alcançar seu objetivo; entretanto, em geral, um indivíduo atribui a si um agenciamento tão somente a partir de sua vontade de realização, sem mostrar como produz efetivamente o evento ocorrido. Assim ocorrem a "dança da chuva" e as práticas mágicoreligiosas. É comum que a atribuição de agência intencional seja um equívoco de percepção dos indivíduos (Malafouris, 2008, p.26). A necessária verificação da ocorrência de uma agência não coincide com o julgamento subjetivo do sujeito. ${ }^{3}$

A marcante obra Material agency (2008) faz um inventário crítico do conceito de "agência" e das dificuldades de as ciências humanas aceitarem a agência como uma atribuição das coisas materiais. Nas ciências sociais, o conceito aparece referido ao jogo estrutura-agência, e as discussões giram em torno dos limites para a liberdade de ação dos indivíduos. O debate estrutura versus agência deixou um vácuo explicativo e viu as tentativas de superar o fosso com a teoria da prática e as ideias da estruturação, como se deu em Giddens e Bourdieu. O obstáculo mais sério para a aceitação das agências materiais é a consideração de que "os únicos verdadeiros agentes da história são os indivíduos humanos", e que "em suma, a agência é um atributo da substância humana" (Knappett, Malafouris, 2008, p.X).

A intencionalidade prevista para uma agência é a barreira para a participação dos objetos na produção do saber, uma exigência para superar as dificuldades originadas pelo relativismo atribuído a Bloor. O saber sobre algo não pode ser uma atribuição estrita dos seres humanos, como se fosse uma atividade mental; o algo deve participar, o saber decorre do confronto de indivíduos com as coisas. O conhecimento sobre o mundo é uma construção das pessoas, mas o mundo deve estar presente. Como? Dando intencionalidade às coisas do mundo?

Exatamente essa foi a alternativa empregada por Michel Callon, em 1986, ao discutir as relações entre pescadores e vieiras em seu clássico: "Some elements of a sociology of translation: the domestication of the scallops and the fishermen of St. Brieuc Bay". Nesse trabalho, Callon emprega uma retórica abundante em metáforas na qual descreve as vieiras como agentes simétricos aos pescadores, com as mesmas qualidades volitivas de humanos. As vieiras tomam decisões e agem com intencionalidade. Bruno Latour encantou-se com a estratégia e a originalidade calloniana e a incorporou imediatamente. Assim, foi forjado o "princípio de simetria generalizada", que apresenta a agência das coisas em paridade com a agência humana. Infelizmente essa orientação engenhosa permaneceu restrita ao jogo 
metafórico que fornece humor aos textos, porém não especifica como ocorre efetivamente a relação entre "humanos e não humanos" - como diz Latour. A actor-network theory (ANT), daí decorrente, produz interpretações úteis, porém suas metáforas pouco esclarecem como os objetos naturais, as coisas do mundo, agenciam e interagem com os humanos. ${ }^{4}$

A questão do animismo presente nos trabalhos de Callon e Latour já é bem conhecida na historiografia, desde as primeiras avaliações surgidas nos anos 1990. Pickering (1995, p.13) dava voz a uma crítica formulada por Schaffer: "Latour se apoia em um hilozoísmo ilegítimo, ou seja, na imputação injustificada de agência para a esfera não humana". Igualmente há inventários em favor dessa posição em Domenèch e Tirado (1998, p.18-43), na obra Sociología simétrica. Contundente também é a opinião, mais recente, de Rose e Jones (2005, p.24; destaques no original):

A concepção forte da teoria ator-rede para a agência material não é sustentável. A sugestão de Latour de que actantes (incluindo atores materiais) têm de 'subjetividade..., intencionalidade..., moralidade' constitui 'hilozoísmo, uma atribuição de propósito, de vontade e vida à matéria inanimada e de interesses humanos ao não humano'.

Mas é o próprio Latour (2001) quem melhor explicita seu pensamento, ao insistir na simetria hilozoísta entre o agente humano e o revólver, em 2001, ao se perguntar: quem atira? o humano ou o revólver? Sua conclusão é em favor da "intenção" do revólver: "A intenção do revólver, a vontade do revólver e o script do revólver superam os do agente humano" (p.206).

Além do abuso metafórico, os autores da ANT afastaram-se de uma etnografia por apresentar a proposta de simetria de maneira ad hoc. Trata-se de uma hipótese a priori com fortes traços idealistas, pois não decorre do coroamento de um trabalho empírico; ao contrário, ela inaugura uma nova linha de pesquisa. Essa idealização foi o instrumento para se contrapor ao êxito de Bloor com sua simetria entre verdade e erro. Por esse estratagema, o "princípio de simetria generalizada" ampliava a simetria mais restrita de Bloor, o que já é uma clara evidência das disputas que Callon-Latour moveram contra Bloor. Bloor tornara-se o alvo. Latour, nesse confronto, faz referência a Bloor com a ironia que lhe é típica: "Esse programa é triplamente forte. Ele é fortemente crítico, fortemente criticado e fortemente criticável" (Latour, Woolgar, 1997, p.22). Afinal, o impacto do "programa forte" fora tal que Bloor era um ponto de passagem obrigatório para as discussões nos science studies desde 1976. A escolha do argumento central latouriano - em torno de sua simetria que venceria a de Bloor - já parece indicar a predisposição para uma luta. Ele ultrapassaria Bloor. Assim, ocorreram as ousadias de Callon-Latour em suas lutas por reconhecimento. Eles se mostraram adversários mertonianos ${ }^{5}$ de Bloor - uma rotina na academia nas disputas por prestígio.

Na sua crítica ao "programa forte", Latour (1994) se concentra em atacar a perspectiva "social", na qual Bloor estaria defendendo um primado do sociologismo. O princípio de simetria de Bloor seria "fraco", pois só considerava o agenciamento "social", abandonava a natureza, a qual seria "fortemente" considerada somente na versão da simetria de Latour, explicitada em seu Jamais fomos modernos.

A estratégia de combate de Latour contra o "social" pode ser acompanhada nas sucessivas edições da obra que o lançou internacionalmente, Laboratory life: the social construction of 
scientific facts (Latour, Woolgar, 1979). Na segunda edição (Latour, Woolgar, 1986), ele apagou qualquer vestígio do termo "social", até mesmo no título, Laboratory life: the construction of scientific facts. Latour refez ainda o seu primeiro capítulo para a edição francesa, de 1988, traduzida para o português em 1997, quando reforça sua postura de combate e de ultrapassagem à simetria do "programa forte" dos sociólogos. Nessa edição, ele se mostra ferrenho opositor ao uso do termo "social" que, em sua opinião, seria a característica do "construtivismo social" de Bloor. Entre 1979 e 1988, Latour dedica-se a traçar sua nova orientação, que será coroada com a "teoria ator-rede". Com a novidade, o sucesso da ANT foi alcançado plenamente, e Latour tornou-se o mais influente autor dos science studies.

Apesar do respeito auferido pela ANT e por Latour, a solução proposta não nos serve; ela é ineficiente para mostrar como as coisas e as pessoas se articulam. E ainda o é pela intencionalidade atribuída às coisas - sejam lombadas, vieiras, armas, bactérias ou portas - e devida a seu idealismo subjacente. Humanos e não humanos equiparados ontologicamente criam um contrassenso; essa simetria retira das pessoas sua qualidade fundamental, a historicidade, e impede que o caráter distintivo dos humanos anotado pelas ciências históricas ocorra. Além disso, como relata Tim Ingold (2008) em sua fábula da aranha e da formiga, criticando a ANT, o uso genérico da expressão "não humanos" para agrupar animais, coisas inanimadas e outras formas de vida cria dissonâncias prejudiciais ao entendimento das ações envolvidas. Diz Ingold (p.214), "eu não posso aceitar seu princípio de simetria", o "conceito de agência deve ter em conta a real complexidade dos organismos vivos em oposição à matéria inerte". Os organismos vivos possuem um sistema nervoso que lhes permite movimentos motivados por sua atenção sensível, e é esse movimento direcionado pela atenção que os qualifica como agentes. Não é pela intenção que se caracteriza a agência, mas "pelo movimento corporal associado à percepção", afirma Ingold; "é simplesmente um absurdo colocar um grão de areia e um pulgão na mesma escala e afirmar que eles são equivalentes" (p.214).

Ao abandonar a exclusividade humana para a agência e a ANT como alternativa, retornamos à estaca zero, porém sem os impedimentos à proposta da agência material. Necessitamos de uma compreensão de agência sem o apelo restritivo ao caráter intencional, que impede uma agência "não humana" para os objetos e sem qualquer "princípio de hilozoísmo generalizado". Precisamos de outra possibilidade para trazer as coisas do mundo, animadas e inanimadas, para a cena de produção dos saberes, tanto o da ciência quanto o de qualquer outra forma de saber. Somente assim poderemos fazer uma história da ciência com sujeito e com objeto. Esse é o nosso roteiro para vencer tanto o relativismo quanto o realismo.

As formas idealistas do fazer historiográfico esgotaram-se. A atitude historiadora hoje exige mais, exige mais etnografia e mais alinhamento ao practical turn. ${ }^{6}$ Estamos ante sérias dificuldades que acarretam a necessidade de uma renovação do olhar do pesquisador dos estudos de ciência. E esse é o nosso desafio para vencer o relativismo de uma ciência sem objeto.

\section{A agência material e seu aspecto simbólico}

Apresentamos aqui uma solução para esse imbróglio, rigorosa e bastante simples. Ela observa mais criteriosamente os conceitos fundamentais das práticas humanas que produzem 
conhecimento na história e na ciência. Defendemos a perspectiva pragmática na qual o jogo societário é considerado uma interação múltipla: dos agentes sociais entre si e desses com o mundo que os cerca. Há confronto entre pessoas e delas (como sujeitos) com a materialidade do mundo (como objeto percebido historicamente). Knorr-Cetina (1997) já incluía os objetos como agentes, ao lado dos humanos. A maior dificuldade para essa perspectiva é evidenciar a existência das agências materiais. Mas as agências materiais estão aí no mundo, em nosso cotidiano. A agência deve ser considerada um fenômeno causal e relacional (Malafouris, 2008); ela não se define pelas intenções, mas pelas consequências, pelos efeitos de sentido produzidos.

Estamos tão habituados a entender o agenciamento como um ato volitivo de humanos, que as mais óbvias e cotidianas ações materiais, tal como a exercida pelo ar que respiramos, passam despercebidas, tornam-se invisíveis. Ou as mais impactantes coerções realizadas pelo mundo natural - como as produzidas pelo sol e pelos elementos climático-meteorológicos. A rotina do movimento solar aparente no horizonte é uma das mais primárias determinações causais dos ciclos diários do nosso metabolismo e da vida em geral. O sol (a causa) é o agente responsável pela sucessão de estados de alerta diurno e de adormecer noturno (seus efeitos) para grande parte das formas de vida. O tipo de sociedade que se ergue em uma dada região é extremamente dependente das condições geoclimáticas e meteorológicas, das interações com seu ambiente físico. Lucien Febvre, Fernand Braudel e muitos outros historiadores já observaram essa pertinência da agência material na constituição da história humana. Ao lado da sociologia ambiental de Lisa Asplen (10 ago. 2006), uma história ambiental trataria das precondições - entre outros aspectos - que condicionam o evolver histórico dos agenciamentos materiais sobre a sociedade e da ação desta sobre o meio ambiente.

Além desses aspectos típicos de contato físico da agência material, há outros mais sutis, que inesperadamente "afetam" os viventes em seus fazeres cotidianos (Derrida, 1999, p.13). Uma agência material - entre coisas e humanos - ocorre sempre que o objeto "afetar"7 uma pessoa. São interações situadas em cenas específicas da vida, nas quais o ambiente físico oferece soluções para o viver. Imagine-se o homem primitivo em suas andanças e que se depara com uma gruta protetora ao cair de uma noite fria e chuvosa. Esse abrigo imprevisto é o resultado de uma agência sobre o indivíduo nômade. A natureza afetou, apresentou sua sugestão de uso, fez sua indicação de uma aplicação prática para aquela gruta, sugeriu-lhe uma função. Cabe ao indivíduo captar a "recomendação" (Asplen, 10 ago. 2006, p.327) feita, dar-lhe significação e simplesmente usá-la. ${ }^{8}$ E essa "recomendação" significativa é causal, produz efeitos de sentidos no sujeito. É o que ocorre com a descoberta súbita de um rio piscoso, de uma árvore frutífera, de uma manada de ruminantes domesticáveis. Todas sugerem algum tipo de atividade, de prática auxiliar da sobrevivência, como a pesca e a agropecuária. Uma forma de vida sempre está inserida em algum ambiente e sofre as coerções e sugestões desse ambiente. Um grupo social passa de nômade a sedentário impulsionado por certas condições materiais. A pecuária e a agricultura são recomendações de possibilidades ofertadas pela natureza.

Essa interação homem-natureza não solicita espaço para ações intencionais, nem do homem nem da natureza, ela é um exemplo de como a agência material ocorre ao estimular certas práticas e estilos de ação adotados pelas formas de vida (Wittgenstein, 1994; Lash, 2001). Nesse caso, a materialidade do mundo estabelece não só coerções e limites, mas apresenta também novas possibilidades para o agir e viver humanos; o meio ambiente se 
apresenta como recurso material para sustentar a sociedade. A agência material "recomenda", ela é causa de transformações no viver social, ela oferece soluções capazes de ser "lidas" pelos sujeitos. Assim, a agência material, com sua significação, invade e transita pelo registro simbólico. Ela promove as habilidades técnicas, os hábitos e costumes desenvolvidos a partir do que é oferecido pelo ambiente. Os conceitos de "afetar" e de "recomendação" demonstram uma qualidade essencial dos agenciamentos materiais: eles são causais e relacionais, vale dizer, recíprocos. Os sujeitos também participam ao lhes dar significados.

Parece-me evidente que se deva considerar a ação das coisas sobre as pessoas ao lado da típica intervenção dos "humanos" sobre os objetos. Afinal, a situação que avaliamos é a de uma interação da qual tudo e todos participam: pessoas e coisas, natureza e sociedade. Contudo, é uma ofensa à descrição etnográfica supor - tal como Latour apresenta - uma simetria idealizada e preexistente à cena que se tenta descrever. O grande desafio para uma descrição mais fidedigna à historicidade do saber científico é mostrar como as coisas atuam sobre as pessoas, como efetivamente ocorre uma agência material sobre os "humanos" e como os agentes naturais interferem na produção do saber. Ou seja, como portas, lombadas na estrada, moluscos e bactérias agenciam e participam dessa construção. Por seu aspecto simbólico, a agência material é recíproca, necessariamente; coisas e pessoas interagem atuando umas sobre as outras.

Uma clara evidência de como a agência material recíproca promove uma ecologia para a integração homem-natureza, sujeito-objeto, dá-se em cada ferramenta e utensílio fabricado desde os tempos mais arcaicos. O mesmo pode ser encontrado nos instrumentos e aparelhos técnicos mais recentes. Cada artefato produzido é uma consequência, um produto acabado do agenciamento ocorrido. A ferramenta decorre da interação homem-natureza, ela é uma produção humana, porém, simultaneamente, também é um produto natural. Desvenda-se a agência fazendo a etnografia desses artefatos, uma etnografia da fabricação e das utilizações das ferramentas. ${ }^{9}$ Assim, cada ferramenta fornece o "corpo", a materialidade de uma agência, e representa também uma habilidade humana situada historicamente, uma habilidade que ocorre no espaço simbólico e que obedece às "recomendações" do agenciamento material. E essa reunião do material com o simbólico dá-se tanto na fabricação quanto no uso de algum artefato, nas regras de seu manuseio. Malafouris faz a etnografia da produção de um vaso de cerâmica e segue a ação recíproca entre os dedos do oleiro e a argila - apesar de o oleiro declarar que a peça é de sua autoria intencional. ${ }^{10} \mathrm{O}$ agenciamento é uma ocorrência relacional entre a habilidade do oleiro, a pasta de argila, a água, a roda etc. Há uma reciprocidade causal nessa produção que ocorre tanto no espaço físico quanto no simbólico. O oleiro retira e armazena significações de sua experiência e pode repassá-la para um aprendiz. Essas significações são formas simbólicas decorrentes e anexas à ação concreta, material. O mesmo ocorre com uma pedra lascada, um osso que se lapidou, uma lança produzida a partir de um galho, todas são formas de agências que pertencem simultaneamente ao mundo dito natural e ao mundo simbólico da cultura. Tal situação ocorre também com produtos mais elaborados em nossa era industrial, como o ato de dirigir um automóvel, usar um computador, operar um tomógrafo etc. O evolver humano pode ser descrito como o desenvolvimento das suas ferramentas, das formas de agências nas quais o ser histórico se envolveu desde a pré-história até os dias atuais. 


\section{O trabalho: a agência recíproca é intra-ativa}

Ao produzir uma ferramenta - que amplia as intervenções humanas no mundo -, o indivíduo teve de desenvolver uma maneira interativa de ação no mundo. Cada ferramenta já se apresenta como solução de um problema causado pelo enfrentamento homem-natureza. É, no entanto, uma solução extraída do mundo. Ou seja, a ferramenta decorre de algo preexistente no mundo que por si já afeta aquele indivíduo e, ao afetar, já se apresenta como uma ação da coisa sobre o indivíduo, em ação recíproca. Ao "inventar" uma lança usada na caça a partir de um tipo de galho arbóreo, o hominídeo primitivo foi afetado pela "recomendação" sugerida e teve de se submeter às propriedades materiais daquele pedaço de madeira, à sua rigidez e à sua plasticidade. Assim descortinamos o movimento inaugural da história: os indivíduos buscam satisfazer suas necessidades ao trabalhar a natureza, atendendo suas recomendações.

Essa consideração nos encaminha para a noção relacional de trabalho, uma ação coletiva que realiza a integração homem-natureza. No trabalho, tudo e todos se transformam e participam em uma "comunidade de práticas" (Ahearn, 2001, p.127). As coisas e os homens se fazem e se refazem, integram-se. Tudo e todos são atores, ou melhor, agentes, coisas e pessoas. O trabalho é a agência por excelência, é uma ação interativa recíproca. É pelo trabalho que o ser humano transforma a natureza e transforma a si próprio. Isso nos leva ao dístico clássico da teoria da práxis: a história é o processo de criação do homem pelo trabalho humano.

Antes de tudo, o trabalho é um processo de que participam o homem e a natureza, processo em que o ser humano, com sua própria ação, impulsiona, regula e controla seu intercâmbio material com a natureza. Defronta-se com a natureza como uma de suas forças. Põe em movimento as forças naturais de seu corpo - braços e pernas, cabeça e mãos -, a fim de apropriar-se dos recursos da natureza, imprimindo-lhes forma útil à vida humana. Atuando assim sobre a natureza externa e modificando-a, ao mesmo tempo modifica a sua própria natureza (Marx, 2002, p.211).

Não há separação entre um universo interior, mental, e outro corpóreo, material. Há uma unidade interativa. Pelo trabalho o homem se relaciona com a natureza e com os outros homens. Não há somente ação subjetiva, há também uma objetividade interativa, está-se ante um realismo prático, um agential realism. ${ }^{11}$ Transforma-se efetivamente o mundo, a natureza, e transformam-se simultaneamente os homens, as relações que eles estabelecem entre si. Da pedra lascada à polida, do fogo à panela, da coleta e caça à agricultura e à pecuária, há uma série de etapas de trabalho material e mental. Um evolver de agências. Formas sucessivas de agenciamento que movimentam a história. Produzem a humanização do homem e alteram simultaneamente a superfície do planeta. O mundo, antes de ser compreendido como conjunto de fatos, é um mundo de agências; como se refere Pickering (1995, p.6), "o mundo não é preenchido, em primeira instância, com fatos e observações, mas com agência", um mundo de trabalho.

No impasse erigido pelo confronto entre realismo e relativismo há que resgatar o que faz sentido em ambos e descartar os seus equívocos. Para tanto, é preciso incorporar os fatores materiais às práticas restritivamente denominadas discursivas, como se não fossem também materiais. Nossa alternativa vai em direção do encontro da materialidade com a literalidade. 
Trata-se de uma proposta de agência simbólico-material decorrente da pragmática, do uso da linguagem. É na prática concreta das ações humanas que se ultrapassa o dilema realismorelativismo. Trata-se de "práticas material-discursivas" (Barad, 1999, p.2), ou seja, práticas que ocorrem no registro simbólico das "recomendações" percebidas e incorporadas na rotina societária.

Karen Barad $(1999,2003)$ promove uma "teoria" da prática e desenvolve uma notável hipótese para as agências. Ela usa o termo "intra-ativo" para designar o caráter interativo dos agenciamentos; trata-se, porém, de uma interação entre partes, mas que é, também, constitutiva dessas mesmas partes. Assim, os agenciamentos são mais do que simplesmente interativos, são "intra-ativos", pois produzem novos sujeitos, ${ }^{12}$ exatamente como ocorre entre natureza e sociedade por ação da tecnologia ou do saber científico. A tecnociência é uma prática "intra-ativa", pois produz uma nova sociedade e uma nova natureza. ${ }^{13}$ Os sujeitos se fazem novos sujeitos, transformados enquanto interagem. Assim, uma agência pretensamente isolada em um único sujeito-agente é um equívoco, pois sempre haverá outro agente com uma ação recíproca, e a agência - "intra-ativa" - será constitutiva de ambos.

Dessa forma, aquilo que denominamos humano nada mais é que o produto de longas interações - "intra-ações" - desde os diversos grupos primitivos com o ambiente natural, "intra-ações" que fizeram o sujeito Homo sapiens. "O processo de tornar-se homem efetua-se na correlação com o ambiente... que é ao mesmo tempo um ambiente natural e humano" (Berger, Luckmann, 1974, p.71). Não nascemos Homo sapiens, nos tornamos - por meio das práticas "intra-ativas".

O conceito de "prática" é uma vacina contra as deformações produzidas pela noção de representação mental utilizada como modelo idealista para a ação humana. A prática envolve de forma interativa mente e corpo, espírito e matéria, é uma intervenção no mundo, é pensamento e ação que ocorrem em situações historicamente determinadas. A prática é a maneira pela qual as existências se realizam no mundo. As vivências, os hábitos e os costumes são concretizações das práticas rotineiras que estabelecem a historicidade de cada indivíduo. A prática nunca é um ato isolado de um agente solitário, mas sempre atua em algo e situa-se em um contexto de ação. É por meio da prática que as percepções do indivíduo sobre si e sobre o mundo se fazem. É nela que as significações que dão sentido aos eventos da vida ocorrem, elas são estabelecidas para toda e qualquer existência e orientam novas práticas societárias. É o ponto de encontro da subjetividade com a objetividade, é uma ocorrência no mundo. Sherry Ortner (1984, p.127) já fazia a sua defesa e propunha que o estudo da prática fosse o estudo de todas as formas de ação humana.

Argumentarei que um novo símbolo-chave de orientação teórica está aparecendo e que pode ser chamado de 'prática' (ou 'ação' ou 'práxis'). Nem sequer é uma teoria ou um método em si, mas, como eu disse, um símbolo, o nome sob o qual uma variedade de teorias e métodos está sendo desenvolvida.

Nesse envolvimento com a perspectiva da prática, já nos deslocamos para os bastidores compreensivos das teorias representacionais. Uma representação dita mental nunca é estritamente mental, mas é engendrada por uma prática societária que a autoriza e enforma. As representações são produtos de formas de vida, ${ }^{14}$ organizam e dão sentido às existências. 
As representações emergem de práticas vivenciais e reafirmam essas vivências. São meros sintomas de práticas.

\section{A linguagem mais que literal, um agenciamento}

O fazer da ciência realiza-se na prática, em seu registro simbólico. Nesse registro é que o trabalho se torna produção de significações e o trabalho produz sentidos; sentidos que se expressam em linguagem. Assim, estabelecemos a relação de intimidade entre palavras e coisas dada pela associação entre as significações e o trabalho que ocorre em cada agenciamento. Barad (2003, p.818) utiliza a noção de "práticas discursivas" para mostrá-la como constitutiva da relação do material com o simbólico, além, também, de constituir o sujeito do conhecimento e o objeto a se conhecer.

As práticas discursivas e os fenômenos materiais não estão em uma relação de exterioridade um com o outro; ou melhor, o material e o discursivo implicam-se mutuamente pela dinâmica da intra-atividade. Porém não são redutíveis um ao outro. A relação entre o material e o discursivo é de implicação recíproca... matéria e significação estão em articulação mútua. Nem as práticas discursivas nem os fenômenos materiais são ontologicamente ou epistemologicamente prévios. Nenhum pode ser explicado em termos do outro, nem possui status privilegiado na determinação do outro (Barad, 2003, p.822).

A noção de prática não remete exclusivamente às ações físicas; a prática humana avança para além da materialidade, transita pelas significações que ela própria impõe ao mundo; significações capturadas pelos demais agentes que partilham tal experiência. Ao assentar fiadas de tijolos com argamassa um pedreiro realiza um trabalho que possui uma significação, para ele e para um aprendiz: ele levantou uma parede segundo um determinado procedimento. Ao partilhar essa operação, o aprendiz pode capturar os significados de cada etapa e, quiçá, repeti-la.

Diremos que as atividades humanas decorrem de "práticas compartilhadas" articuladas a significações igualmente partilhadas. ${ }^{15} \mathrm{E}$ essas significações já constituem uma linguagem linguagem em sentido lato, constituída pelo conjunto de significações. Em nosso combate ao mentalismo, repensamos como as práticas discursivas e até mesmo a linguagem logocêntrica linguagem em sentido estrito, em sua literalidade - estão imbricadas com as experiências concretas de vida dos falantes. Leroi-Gourhan (1990, p.116-117) ainda avança mais ao mostrar historicamente como a linguagem atua como uma ferramenta; ela é um instrumento de execução das atividades humanas nessas práticas compartilhadas. ${ }^{16} \mathrm{~A}$ linguagem deixa de ser vista como constructo da mente dos indivíduos e é observada como processo integrado às práticas materiais de uma coletividade. A ideia de uma linguagem se expande para além da linguística, ganha materialidade e avança pela etnologia. A linguagem, nesse sentido ampliado, um sentido lato, será conceituada como aquilo que porta e articula as significações apreendidas pelos sujeitos, sejam apreensões de sentido literal, dado por palavras, ou de sentido semiológico, dado por objetos ou pela articulação de objetos. Trata-se da linguagem mais que literal, que se apresenta como conjunto de significações. Como diz Barthes (1989, p.133), "os próprios objetos poderão transformar-se em fala se significarem alguma coisa". Derrida $(1999$, p.10) ratifica essa compreensão mais que literal ao designar o termo "escritura" como 
algo que excede e compreende a linguagem literal e que envolve "tudo o que pode dar lugar a uma inscrição em geral, literal ou não" (p.11). Tais significações colocadas nas inscrições derridianas são sentidos, semiológicos.

A ideia de representação apoia-se na linguagem literal, logocêntrica, que servia de garante para se privilegiar o universo mental como que encerrado em si mesmo. Tínhamos a linguagem em sua clausura. Essa "visão mentalista da linguagem" era considerada traço diferencial humano que o pressupunha como "o ser autônomo da linguagem", posto que racional. Invisto contra a ideia de linguagem como elaboração psíquica e, com o conceito de prática, penso a linguagem como enlace "intra-ativo" que conjuga o material e o simbólico. As chamadas práticas discursivas abrangem mais que o caráter literal de um discurso: são efetivamente práticas simbólico-materiais.

Necessitamos de uma compreensão de agência - e de trabalho - em toda a sua abrangência. A agência humana que atua na materialidade também é uma atividade simbólica, tal como uma ferramenta, que, além de ser um objeto material, é também um artefato simbólico. Toda ferramenta que participa de um fazer também é um saber construído por significações. Há significações em cada operação agenciadora, e essas significações formam toda e qualquer expressão linguística. Assim, afastamo-nos da ideia de linguagem como produto mental e a compreendemos como forjada pelas significações que agenciam - a linguagem mais que literal.

Tal linguagem deve ser entendida como prática, integrada ao trabalho, pois toda agência é produtora de sentidos: ela produz significações no mundo e, simultaneamente, extrai significações do mundo. Não se pode suprimir do trabalho a sua expressão simbólica, é o que lhe dá sentido. O trabalho sem suas significações é vazio e perde a razão de sua existência. Ele é simultaneamente uma operação simbólica e material, imprime sentidos, inscreve uma significação na coisa.

\section{O encontro etnográfico das coisas com as palavras, um encontro realista e relativista}

Como as coisas do mundo são apreendidas pelos sujeitos falantes? Como a materialidade veste-se em literalidade? Como as coisas encontram as palavras?

Vamos em busca da cena originária hipotética que envolve o encontro das coisas com as palavras, vamos para esse tempo anterior ao da palavra. Focalizemos a cena corriqueira na qual esse encontro misterioso ocorre. Esse evento se materializa em inúmeras situações em nossas práticas diárias, seja pelo impacto inesperado - antes de sua nomeação - de uma gota de chuva no rosto ou por um ruído súbito não identificável, ou por um aroma incógnito, ou pelo surgimento de uma sombra imprevista... Algo, ainda desconhecido e enigmático, aconteceu, mas aconteceu o quê? Ainda não se sabe; só se percebe que ocorreu um algo diferente. Esse algo é um simples "traço" perceptível (Derrida, 1999). Aquelas percepções são traços que afetam o sujeito. Eis aí e assim o momento em que o mundo real surpreende e invade a cena de vida de cada sujeito, eis como o real - não simbolizado, não verbalizado - mostra-se à realidade humana, histórica. Lacan faz uma útil distinção entre real e realidade, na qual o real precede a linguagem e a letra, e até resiste à simbolização. Já a realidade - um constructo histórico suga o real para dentro da linguagem, para o interior dos signos destinados a escrevê-lo 
e, dessa maneira, dá-lhe valores, torna-o realidade. Porém o real hipotético está sempre lá, fora da linguagem, "separado de nossa realidade" (Fink, 1998, p.44), pronto para invadi-la. ${ }^{17}$

Eis a nossa versão da fábula do evento primordial: "E no princípio, antes do Verbo, era um simples traço diferencial...", no qual a coisa mostra-se apenas como diferença, um rastro sem a presença de qualquer significação - tão somente a sua diferença é percebida. É um algo, uma coisa, que afeta nosso aparelho sensório.

E esse fabular cênico é estritamente relacional, entre o traço e o sujeito afetado. O traço tão somente marca uma diferença; ele não remete a nada. O traço "real", um vestígio do Real, atravessa a realidade historicamente constituída e pode ser percebido pelo agente nessa realidade. No entanto, o traço se encontra aquém das palavras, é simplesmente uma diferença que "se anuncia como tal" - declara Derrida (1999, p.57), "é preciso pensar o rastro antes do ente". ${ }^{18}$

Ao considerar de maneira mais concreta essa invasão do real do mundo "extralinguístico" no cenário das ações humanas, permaneço aqui, agora, refletindo ao escrever essas palavras, enquanto observamos uma ultrassonografia preenchida por manchas desiguais, por traços, rastros derridianos, na qual as manchas de claros e escuros não me remetem a nada. Para a nossa observação leiga, esses traços só mostram diferenças visuais de tons. Um especialista, contudo, delineou com sua caneta um contorno e anexou-lhe uma designação: "feto no quinto mês". Ele nomeou uma diferença exposta pelo traço; a diferença constituída no traço tornou-se significante. As formas de significação partem da captura da diferença, do traço que se institui (Derrida, 1999, p.80). Após a nomeação, a coisa se fez um ente - uma presença, um objeto. Porém, para que o traço se faça uma presença é solicitada a participação de um sujeito. De um sujeito afetado pelo traço. Ante a ultrassonografia, o leigo naquela prática é afetado por manchas: ele vê manchas. Já o especialista na prática que produziu aquele artefato, a ultrassonografia, é afetado por um "contorno fetal" que lhe é visível: ele vê um feto. Ele vê o feto, por ser sujeito em uma prática discursiva, uma prática na qual a palavra "feto" já circula semanticamente em um estilo de pensamento fleckiano. Esse estilo, por sua vez, já conduz uma taxonomia para o mundo, taxonomiza a realidade histórica constituída naquela prática, naquele coletivo de pensamento, por intermédio do Gestaltsehen ${ }^{19}$ - essa a sua condição sine qua non, isto é, a condição para nomear o traço, para identificar o traço no protocolo de sua prática discursiva, a qual o submeterá à sua gramática.

Aquele traço afeta tanto o leigo quanto o especialista, como pura diferença percebida como tal, porém cada um desses sujeitos resolve essa percepção dentro do seu próprio universo discursivo, de sua semântica, de seu léxico, enfim, de suas condições históricas de subjetivação. São sujeitos históricos que trabalham no interior de suas respectivas historicidades constitutivas, de seus coletivos/estilos de pensamento. O leigo nomeia "mancha", o especialista, "feto". Uma percepção para cada Gestaltsehen. O real do traço é conduzido para o interior da realidade simbólica; ele invade e atualiza a realidade histórica. Assim o traço ingressa na linguagem: torna-se uma "inscrição" (Derrida, 1999, p.11), recebe o batismo simbólico, das palavras. Por meio do Gestaltsehen, o traço "abre o aparecer e a significação" (p.80). Eis o salto de coisas a palavras. A coisa-objeto, ativa, irrompe na cena e mostra-se ao sujeito passivo. Esse é o fracasso do relativismo: a coisa, o objeto, participa ao 
afetar o sujeito. Há um agenciamento material concreto dado pelo traço, algo extrapola as subjetividades e o "real" do objeto agencia os sujeitos. Recupera-se, aqui, algo comum ao realismo científico, porém, agora, com uma distinção fundamental em relação a esse realismo: o sujeito também atua ao inscrever o traço na realidade. O sujeito, submetido à coerção de seu estilo de pensamento, "vê" o sentido dado por aquela inscrição ao estar ante o traço. Ao contrário da compreensão realista, a inscrição - realizada pelo sujeito - obedece ao código do relativismo, é subjetiva também. Realismo e relativismo misturam-se e se descaracterizam.

\section{Pessoas, coisas e objetos são, todos, agentes ativos}

O ingresso do traço na realidade solicita três componentes: um traço diferencial (que afete um sujeito em sua percepção), uma linguagem (que já constitua uma prática discursiva e que decodifique aquela percepção) e um sujeito da linguagem (que seja afetado pelo traço). Não há o sensível em si, simplesmente pelo fato de o sujeito já estar integrado a um estilo de pensamento. As percepções do sujeito estão sempre acompanhadas de sua capacidade de extrair significações as quais dependem de seu estilo de pensamento. Fleck considera os mesmos três componentes na produção do conhecimento. ${ }^{20}$

A mera designação ou indicação gestual de um traço do mundo já lhe imprime significação, um uso, uma função, uma aplicação, uma classificação. Uma nomeação é seletiva, recorta e focaliza, seleciona um entre muitos, designa a diferença do traço, destaca-o de seu entorno de contrastes. Já o veste de cultura, impõe-lhe uma nomenclatura, declara-o objeto e lhe inscreve um sentido. Torna-o uma presença: presença objetal, presença textual. E essa inscrição (Derrida, 1999, p.11), doravante, será inseparável daquele objeto, o que permitirá sua leitura. Diremos que a significação está colada ao objeto, e essa inscrição é que garante a linguagem mais que literal realizada por um sujeito. Esse encadeamento que decorre da agência material é invisível na perspectiva latouriana.

O objeto nomeado não mais se apresentará em seu "estado de natureza", despido, incógnito, amorfo. Ele estará situado na contraluz de diferenças e semelhanças que o evidenciam. Será visto, percebido, reconhecido, lido, pensado com e por meio de sua inscrição. O objeto tornase um agente. Assim o relativismo encontra seu destino e se submete ao realismo. O objeto interfere na produção do saber e na ação do sujeito que permanece ativo. Ambos, sujeito e objeto, participam. Realismo e relativismo se descaracterizam e se fundem.

Não há palavras em oposição a coisas, objeto de um lado e palavra do outro; há uma unidade: uma coisa-objeto-palavra que produz vínculo entre o sujeito e o objeto; o objeto tal como a palavra - afeta. A significação enlaça, em sua unidade simbólico-material, aquele/ aquilo que foi afetado. Para ver o objeto é necessário distingui-lo. E sua distinção inscrita como significante, literal ou não, acena para o leitor, torna-se um signo. O mesmo ocorre com a impressão de uma forma diferencial sobre um objeto, como a modelagem de uma peça de cerâmica compondo um vaso. A forma "vaso" torna-se uma escritura-inscrição derridiana ${ }^{21}$ para o sujeito usuário de utensílios. Não há mais argila em si, de um lado, em "estado de natureza", e a forma ideal platônica "vaso", de outro. Elas compõem agora uma unidade, um objeto com inscrição, ainda que não literal. O design - sua forma e atribuição utilitária, sua 
função - inscreve-se na argila, lhe é inseparável. E essa forma percebida que afeta o sujeito, justamente por afetar o sujeito, está na transcrição literal "vaso". A forma que afeta - o design - e a designação literal "vaso" são, ambas, inscrições. A fidelidade dessa transcrição, de uma inscrição não literal para uma literal, é garantida pela continuidade do sentido estabelecido pela affection derridiana, naquela relação do sujeito com a inscrição da coisa. Tanto o design quanto a palavra "vaso" portam o mesmo sentido para o sujeito afetado que poderá ler ambos. Os objetos do mundo eclodem pelas inscrições que lhes dão sentido, sejam elas literais ou não, os objetos "falam" seus significados (Barthes, 1989, p.133). O conceito de "escritura", uma linguagem mais que literal, excede e abarca o de linguagem literal (Derrida, 1999, p.10). O mundo transforma-se em um texto a ser lido pelo sujeito. Assim, por meio da agência das coisas, a materialidade veste-se em literalidade, o que nos autoriza dizer "tudo é texto".

\section{Considerações finais}

A agência material, neste artigo, é uma panaceia. Ela enfrenta com sucesso as principais endemias que assolam o território das ciências sociais e humanas em nossa contemporaneidade. Ela nos imuniza contra o relativismo e o realismo. Ela evita o contágio dos males do idealismo que nos impõe visões distorcidas da realidade por meio das dicotomias sujeitoobjeto, sociedade-natureza e mental-material. Falar de agência para as coisas é considerar que os elementos materiais são indispensáveis para a consecução integral do processo de conhecimento. Assim, ficam reunidas sociedade e natureza.

A originalidade deste artigo ao defender o agenciamento material para a análise histórica da ciência não se encontra na materialidade concreta das agências, no plano meramente físico, como é o caso da radiação solar sobre os organismos. Também não se encontra nas ações de contato mecânico entre sujeito e objeto. A novidade é seu ingresso no registro simbólico; esta é sua originalidade: supor que os objetos fazem recomendações, que eles afetam os sujeitos. Os sujeitos extraem significações dos objetos. Cada recomendação leva um significado para o sujeito, ou seja, sujeito e objeto estão integrados. A relação sujeito-objeto é caracterizada por ocorrer tanto no registro material quanto no simbólico. Tal fato torna possível adestrar animais afetados pelos instrumentos simbólicos do adestrador. Essas são agências recíprocas. A materialidade veste-se pelo simbólico, ganha significações que propiciam a linguagem mais que literal. As coisas podem ser lidas como textos pelo sujeito.

Dessa forma, a agência material recíproca torna-se o instrumento que vence tanto o relativismo societário quanto o realismo, das "verdades naturais". Mediante esse agenciamento, chega-se a um conhecimento que incorpora tanto alguns aspectos do realismo quanto do relativismo. Poder-se-ia dizer que o conhecimento é realista e também é relativista.

O conhecimento é composto por uma leitura subjetiva realizada pelo sujeito (tal como propõe o relativismo) e por uma affection derridiana objetiva do objeto (como é do gosto do realismo). Assim, tanto o objeto quanto o sujeito suportam os papéis de ativo-passivo. Enquanto no realismo, que persegue a objetividade idealizada, o objeto é o agente ativo e o sujeito, um elemento passivo, no relativismo, o sujeito com sua subjetividade mostra-se ativo, e o objeto não participa, é inerte. Em nossa proposta, no entanto, relativismo e realismo se embaralham e perdem suas características de exclusividade. 
O conhecimento conjuga, ao mesmo tempo, as coisas da sociedade e as da natureza. Não há dicotomias excludentes: sociedade e natureza formam um todo integrado, tal como ocorre também com mente e corpo. Enfim, sujeito e objeto constituem-se como uma unidade interativa.

\section{AGRADECIMENTOS}

Agradeço aos avaliadores, aos editores e ao revisor as inúmeras sugestões recebidas. Elas melhoraram a compreensão do texto, tornando-o mais claro, facilitando a apreensão crítica de minha proposta.

\section{NOTAS}

${ }^{1}$ Essa é uma denominação corrente dos estudos de ciência nas décadas de 1940 a 1970. Bloor (1991, p.12, $14,17,24)$ emprega a expressão sociology of error diversas vezes.

${ }^{2}$ Bloor (1991, p.33) reagiu a seus críticos afirmando que nenhuma sociologia consistente pode apresentar o conhecimento como uma fantasia desconectada da nossa experiência do mundo material que nos envolve.

${ }^{3}$ Malafouris (2008, p.21) indica dois erros na consideração de intencionalidade: "o primeiro é de uma causalidade mental aparente", e o segundo, correlacionado com o primeiro, é a própria "atribuição de agência" a algo derivado do desejo do sujeito. $\mathrm{O}$ autor, bastante crítico da intencionalidade, defende que "agência e intencionalidade não podem ser propriedades nem das coisas nem dos seres humanos, elas são propriedades do enlace material" (p.22) entre ambos.

${ }^{4}$ Apesar de a ANT trazer notáveis contribuições, seu animismo permaneceu como um calcanhar de aquiles. Seria mais proveitoso abandonar o recurso à simetria, como Latour acabou fazendo.

${ }^{5}$ As disputas por prestígio acadêmico são uma motivação para a produção de pesquisas nas diversas áreas acadêmicas, conforme análise de Merton (1979).

${ }^{6}$ Durante a década de 1980 emergiu essa postura historiográfica que incorporava uma visão pragmática do mundo dando prioridade à prática efetiva nas produções societárias, como ocorre em Pickering $(1995,2001)$, Barad (1999, 2003) ou Knorr-Cetina (1997).

${ }^{7}$ Extraio da gramatologia derridiana (Derrida, 1999) a motivação para o conceito de "afetar". Evidentemente, "ser afetado" não é uma qualidade inata do agente; ela depende do aprendizado decorrente de vivências anteriores, depende do estilo de pensamento do agente, como diria Fleck (2010).

${ }^{8}$ Lisa Asplen (10 ago. 2006, p.327), enfatizando o caráter não determinístico da "recomendação", cita o trabalho de Kate Soper (1995): "Como Soper explica, uma agência material 'pode recomendar' certos tipos de ação, e ela sempre terá uma palavra a dizer na determinação dos efeitos de nossas ações".

${ }^{9}$ Ao produzir uma lâmina cortante por meio do polimento de um osso, o agente humano teve de considerar as possibilidades e os limites da peça bruta de osso. Confeccionar uma faca de origem óssea depende desses dois agentes: o homem e o osso.

${ }^{10}$ Ainda que a subjetividade do oleiro creia em sua intenção, uma etnografia mostra que as etapas iniciais da modelagem, desde a preparação da pasta de argila até a quantidade necessária de pasta e sua posição no centro do "trabul" (a plataforma giratória), solicitam informações coletadas de experiências anteriores. O oleiro ganhou essa habilidade ao ser "afetado" pelas "recomendações" da argila. Durante a confecção, a pressão exercida pelos dedos enquanto a roda gira combinada com a umidade correta e a velocidade da roda são componentes fundamentais para a peça permanecer com sua estrutura estável. A argila fornece as indicações para seu manuseio correto. Se a pressão dos dedos for adequada, se a quantidade de água e a velocidade forem aceitáveis, então a peça não se romperá (Malafouris, 2008, p.19-36).

${ }^{11}$ Barad (1999, p.7) designa a "realidade histórica" como agential reality. Dessa forma, fica afastada a ideia de um Real metafísico que desconhece a pragmática das ações humanas. Só temos contato com essa realidade contra a qual nós interagimos e nos constituímos como entes.

12 "A noção de "intra-ação" (em contraste com a usual 'interação', que presume a existência prévia de entidades independentes ou correlacionadas) representa uma profunda mudança conceitual. É por meio de intra-ações agenciadoras específicas que os limites e as propriedades dos 'componentes' dos fenômenos se constituem e que aqueles conceitos consagrados tornam-se significativos" (Barad, 2003, p.815; destaques no original). 
${ }^{13}$ Quando um indivíduo confecciona uma lança a partir de um galho de arbusto, ele está em agência com o arbusto, e a ontologia desse ramo de árvore transforma-se na de um artefato, uma arma. O simples indivíduo agora é um caçador. Caçador e arma são novas entidades constituídas pela agência. Existem - são sujeitos - por estar em interação por meio da agência.

${ }^{14}$ As formas de vida wittgensteinianas constituem um conceito vinculado ao de prática, ver Lash (2001).

${ }^{15}$ As práticas compartilhadas definem a atividade humana. Tomasello $(2003$, p.85, 151, 184) pressupõe a colaboração e o compartilhamento como necessários à cognição - simbólica - mediante "cenas de atenção conjunta". Ver também o conceito de "comunidade de práticas" em Ahearn (2001, p.127).

${ }^{16}$ Leroi-Gourhan (1990) propõe que linguagem e ferramentas são produções integradas entre si, sincrônicas. A criação e o uso de uma ferramenta são acompanhados pari passu pela constituição de uma linguagem.

${ }^{17}$ Uma síntese desse olhar lacaniano encontra-se em Fink (1998), especialmente no capítulo três, “A função criativa da palavra" (p.43-52). Ver também essa discussão em Derrida (1999, p.79).

${ }^{18}$ Derrida utiliza o termo la trace, traduzido por "rastro" em Gramatologia. É pertinente a preferência de Claudia Rego (2006, p.151) pelo termo "traço", pois rastro sugere uma relação figurativa com a marca deixada por um animal. Sigo essa indicação "traço", um termo já usual em psicanálise nas discussões sobre essas questões.

${ }^{19}$ Em Fleck (2010), essa maneira de "ser afetado" é apresentada pelo conceito Gestaltsehen ("ver formativo", o perceber orientado). "A percepção da forma (Gestaltsehen) imediata exige experiência numa determinada área do pensamento: somente após muitas vivências, talvez após uma formação prévia, adquire-se a capacidade de perceber, de maneira imediata, um sentido, uma forma e uma unidade fechada. Evidentemente, perdese, ao mesmo tempo, a capacidade de ver aquilo que contradiz a forma (Gestalt)" (p.142). Eis aí o estilo de pensamento.

${ }^{20}$ Ou seja, o saber já constituído, o sujeito e o "real", ver Fleck $(2010$, p.50-51, 81, 83, 136).

${ }^{21}$ Derrida (1999, p.11) designa por "escritura" "não apenas os gestos físicos da inscrição literal, pictográfica ou ideográfica, mas também a totalidade do que a possibilita; ... tudo o que pode dar lugar a uma inscrição em geral, literal ou não".

\section{REFERÊNCIAS}

AHEARN, Laura M.

Language and agency. Annual Review of Anthropology, n.30, p.109-137. 2001.

ASPLEN, Lisa.

Decentering environmental sociology: lessons from post-humanist science and technology sudies. In: Annual Meeting of the American Sociological Association, 2006, Montreal. Disponível em: http://www.allacademic.com/ meta/p104647_index.html. Acesso em: 18 nov. 2008. 10 ago. 2006.

BARAD, Karen.

Posthumanist performativity: toward an understanding of how matter comes to matter. Signs: Journal of Women in Culture and Society, v.28, n.3, p.801-831. 2003.

BARAD, Karen.

Agential realism: feminist interventions in understanding scientific practices. In: Biagioli, Mario (Org.). The science studies reader. New York: Routledge. p.1-11. 1999.

BARTHES, Roland.

Mitologias. Rio de Janeiro: Bertrand. 1989.
BERGER, Peter; LUCKMANN, Thomas.

A construção social da realidade. Petrópolis: Vozes. 1974.

BLOOR, David.

Knowledge and social imagery. Chicago: University of Chicago Press. 1991.

CALLON, Michel.

Some elements of a sociology of translation: the domestication of the scallops and the fishermen of St. Brieuc Bay. In: Law, John (Org.). Power, action and belief: a new sociology of knowledge? London: Routledge \& Kegan Paul. p.196-233. 1986.

DERRIDA, Jacques.

Gramatologia. São Paulo: Perspectiva. 1999.

DOMÈNECH, Miquel; TIRADO, Francisco Javier (Org.).

Sociología simétrica. Barcelona: Gedisa. 1998.

FINK, Bruce.

O sujeito lacaniano, entre a linguagem e o gozo. Rio de Janeiro: Jorge Zahar. 1998.

FLECK, Ludwik.

Gênese e desenvolvimento de um fato científico. Belo Horizonte: Fabrefactum. 2010. 
INGOLD, Tim.

When ANT meets SPIDER: social theory for arthropods. In: Knappett, Carl; Malafouris, Lambros (Ed.). Material agency. New York: Springer. p.209-215. 2008.

KNAPPETT, Carl; MALAFOURIS, Lambros (Ed.). Material agency: towards a non-anthropocentric approach. New York: Springer. 2008.

KNORR-CETINA, Karin.

Sociality with objects: social relations in postsocial knowledge societies. Theory, Culture \& Society, v.14, n.4, p.1-30. 1997.

KUHN, Thomas.

O caminho desde a estrutura: ensaios filosóficos, 1970-1993. São Paulo: Editora Unesp. 2006.

LASH, Scott.

Technological forms of life. Theory, Culture \& Society, v.18, n.1, p.105-120. 2001.

LATOUR, Bruno.

A esperança de Pandora. Bauru: Edusc. 2001.

LATOUR, Bruno.

Jamais fomos modernos: ensaios de antropologia simétrica. São Paulo: Editora 34. 1994.

LATOUR, Bruno; WOOLGAR, Steve.

$A$ vida de laboratório: a produção de fatos científicos. Tradução da edição francesa de 1988. Rio de Janeiro: Relume Dumará. 1997.

LATOUR, Bruno; WOOLGAR, Steve.

Laboratory life: the construction of scientific facts. 2.ed. Princeton: Princeton University Press. 1986.

LATOUR, Bruno; WOOLGAR, Steve.

Laboratory life: the social construction of scientific facts. Beverly Hills: Sage. 1979.

LEROI-GOURHAN, André.

O gesto e a palavra: técnica e linguagem. Lisboa: Edições 70. 1990.

MALAFOURIS, Lambros.

At the potter's wheel: an argument for material agency. In: Knappett, Carl; Malafouris, Lambros (Ed.). Material agency. New York: Springer. p.19-36. 2008.

MARX, Karl.

O capital: crítica da economia política. Livro 1. Rio de Janeiro: Civilização Brasileira. 2002.

MERTON, Robert K.

A ambivalência sociológica. Rio de Janeiro: Zahar. 1979.

ORTNER, Sherry B.

Theory in anthropology since the sixties.

Comparative Studies in Society and History, v.26, n.1, p.126-166. 1984.

PICKERING, Andrew.

Practice and posthumanism: social theory and a history of agency. In: Schatzki, Theodore; Knorr-Cetina, Karin; Savigny, Eike Von (Org.). The practice turn in contemporary theory. London: Routledge. p.172-183. 2001.

PICKERING, Andrew.

The mangle of practice: time, agency, and science. Chicago: The University of Chicago Press. 1995.

REGO, Claudia de M.

Traço, letra, escrita: Freud, Derrida, Lacan. Rio de Janeiro: 7 Letras. 2006.

ROSE, Jeremy; JONES, Matthew.

The double dance of agency: a socio-theoretic account of how machines and humans interact. Systems, Signs \& Actions, v.1, n.1, p.19-37. 2005.

SOPER, Kate.

Feminism and ecology: realism and rhetoric in the discourses of nature. Science, Technology, and Human Values, v.20, n.3, p.311-331. 1995.

TOMASELLO, Michael. Origens culturais da aquisição do conhecimento humano. São Paulo: Martins Fontes. 2003.

WITTGENSTEIN, Ludwig.

Investigações filosóficas. Petrópolis: Vozes. 1994.

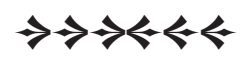

